\title{
Whistleblowing policies and corporate values: a review of Australia's largest corporations
}

\author{
Katrina A. Bramstedt ${ }^{1,2}$ iD
}

Received: 23 August 2021 / Accepted: 20 December 2021 / Published online: 19 January 2022 (C) The Author(s) 2022

\begin{abstract}
Values are the precursors of ethical behaviour. In this research study, Australia's largest securities exchange-listed companies were explored for alignment of their corporate values as published on their public website to their whistleblower policies (WBP). The Corporations Act 2001 requires organisations' WBPs to be externally available to facilitate reporting by former employees and others, yet five organisations $(10.2 \%)$ had not posted their WBP on their corporate website. Most $(n=44$, $89.8 \%$ ) of Australia's 49 largest companies profess corporate values on their public website, but only one also fully replicated their corporate values in their WBP. Two organisations made no mention of their corporate values in either location. Of the 44 organisations which posted their WBP on their corporate website, $29.6 \%$ $(n=13)$ make no mention of their corporate values in their WBP (either specifically or generically as "values"). Most organisations $(70.5 \% ; n=31)$ evidenced weak or no alignment of values across their website and WBP. Notably, 22.7\% $(n=10)$ have a partial listing of their values in their WBP, rather than the full set, and $11.4 \%$ $(n=5)$ have a different/unmatched set of values as compared to those listed on their website. Corporate values such as trust, integrity, safety, respect, and accountability are the ethical buttress of a whistleblowing management system, and when WBPs explicitly express corporate values as fundamental to purposing the policy, this potentially creates a shared values alliance between employees and the organisation voicing support for prosocial behaviours (including whistleblowing).
\end{abstract}

Keywords Values · Whistleblowing $\cdot$ Leadership $\cdot$ Management $\cdot$ Ethics · Compliance

\section{JEL Classification Code M14}

Katrina A. Bramstedt

txbioethics@yahoo.com; kbramste@bond.edu.au; katrina.bramstedt@clarityethics.com

1 Clarity Ethics, P. O. Box 137, Kew, VIC 3101, Australia

2 Bond University Faculty of Health Sciences \& Medicine, University Drive, Gold Coast, Robina, QLD 4219, Australia 
"Setting up an effective whistleblowing program should not be seen as a standalone process. Attention should first be given to a company's ethical value system." (Pascoe 2010, p.372)

\section{Introduction}

\section{Background}

Whistleblower policies (WBP) are corporate governance documents that describe the corporate stance on managing unethical and illegal workplace behaviour (misconduct). These documents are written to align with laws and regulations in the geographic jurisdiction, and they often include the procedural steps for reporting and investigating the misconduct, although these activities can be described in separate procedural documents. More than a list of rules and regulations, a whistleblower policy should describe and embrace ethical values as a corporate strength that is foundational to compliance and a positive workplace (Pascoe and Welsh 2011). Examples of ethical values include integrity, respect, and teamwork. In this way, ethics is the precursor of compliant [ethical] behavior, with ethical behavior mitigating the risk of workplace misconduct.

The Australian Securities Exchange has published a set of corporate governance principles and recommendations for ASX-listed entities (ASX Corporate Governance Council 2019). Although not mandatory, these principles and recommendations are designed as standards for ethical governance for all ASX-listed companies. Notably, the ASX states in Recommendation 3.3, Box 3.3 Suggestions for Content, "Link the [whistleblower] policy to the organisation's statement of values" and "Clearly identify the types of concerns that may be reported under the policy" (ASX Corporate Governance Council 2019, p.17). Overall, the clarity of expected (ethical) behaviours is related to the transparency and alignment of the expected behaviours by organisations across their platforms. In this study, Australia's largest securities exchange-listed companies were explored for visibility and alignment of their corporate values as published on their public website and within their published WBPs.

\section{Literature}

In 2010, Australia's top 200 companies from Standard and Poor's list (publicly traded companies on US stock exchange) were reviewed for their adoption of WBPs and procedures (Pascoe and Welsh 2011). The method involved searching each company's website for their WBPs and procedures. Their results indicated $22.5 \%$ of companies $(n=45)$ had no publicly transparent documents and those companies did not respond to the researchers' requests for information. At that time, there was no regulatory requirement for public visibility of such documents. Accordingly, the researchers acknowledged that the lack of transparency was not an exact indicator that the policy/procedure did not exist, but rather that it demonstrated a "a low level of commitment to governance policies as ideally the programme should be available 
to all existing and prospective stakeholders" (Pascoe and Welsh 2011, p.166). In this same research study, they found that $13 \%$ of companies did not link their WBPs to their corporate code of ethics.

In 2013, a similar Australian study was conducted (Dixon 2016). Specifically, the websites of the top 200 ASX-listed companies were searched for WBPs and corporate codes of ethics. Only $121(60.5 \%)$ WBPs were publicly visible. Neither of these two Australian studies explored the corporate values expressed by the organisation's websites or whistleblower policies, thus the current research adds new knowledge and is reflective of a new regulatory time point for Australia based on revised legislation (Corporations Act 2001 (Cth)) and Australian Securities Exchange standards for ethical governance (ASX Corporate Governance Council 2019).

\section{Methods}

In March 2021, the ASX's 50 largest companies by market capitalisation were identified from their list of nearly 2000 organisations posted online (ASX 2021). These 50 companies were then cross-referenced for their ranking on the Forbes Global 2000 list (Forbes 2021). The public website of each of the 50 companies was reviewed to identify their corporate values. The website was also reviewed for each company's WBP and this document was searched (Chrome browser search tool) and read manually for statements which mention the organisation's corporate values. Values across the paired corporate website and WBP were compared for alignment. Manual reading of each website and WBP was essential to detect values stated in images rather than plain text format. The WBPs were also searched to identify their reference to a corporate code of ethics/conduct.

\section{Results}

News Corporation is listed twice in the ASX Directory with a ranking of 20 (symbol NWS, class B voting shares) and 21 (NWSLV, class A non-voting shares), but it has only one website; thus, for data review it was noted as one company, resulting in 49 companies analysed (Supplementary Information 1). Australia's whistleblowing legislation (Corporations Act 2001 (Cth)) requires the organisation's WBP to be externally available to facilitate reporting by former employees and others, yet in five instances $(10.2 \%)$ the organisation's WBP was not visible on their corporate website (or locatable with a Google search) and thus not included for analysis. Most $(n=44$, 89.8\%) of Australia's 49 largest companies profess corporate values on their public website, but only 1 also fully replicated their corporate values in their WBP. One organisation listed their corporate values in their WBP, but not on their corporate website. Two organisations made no mention of their corporate values on neither their corporate website nor in their WBP.

Of the 44 analysed WBPs, 39 (88.6\%) referenced their organisation's code of ethics/conduct. Of the 44 organisations which posted their WBP on their corporate website, $68.2 \%(n=30)$ evidenced weak or no alignment of values across their WBP 
and website. Specifically, $16(36.4 \%)$ organisations use the generic term "values" in their WBP or post a hyperlink to the corporate values positioned elsewhere. Nine organisations $(20.5 \%)$ have a partial listing of their values in their WBP, rather than the full set. Five organisations (11.4\%) have a different/unmatched set of values in their WBP as compared to those listed on their website. Many organisations (27.3\%; $n=12$ ) make no mention of their corporate values in their WBP (either specifically or generically as "values"). A related study ${ }^{1}$ discusses in detail the 82 values identified on these corporate websites, noting the most common were teamwork (19 companies, 38.8\%), innovation (15 companies, 30.6\%), respect (14 companies, 28.6\%), and integrity (14 companies, $28.6 \%)$.

\section{Discussion}

Australia's whistleblowing legislation requires the organisation's WBP to be visible to internal and external whistleblowers (Australian Securities \& Investments Commission 2019), yet in five instances (10.2\%) the organisation's WBP was not visible on their corporate website (or locatable with a Google search). This is an improvement from the findings of Dixon (2016) which identified 39.5\% of Australian organisations failing to post their WBP publicly. It is likely that the changes in Australian whistleblowing legislation since Dixon's study were the impetus for this this transparency improvement; specifically, revisions to the law in 2019 (Corporations Act 2001 (Cth)) allowed former employees and their relatives or dependents (externals) to file whistleblower disclosures with legal protections, thus corporate policy access is critical.

In the current study, of the 44 organisations which posted their WBP on their corporate website, 39 policies (88.6\%) referenced their organisation's code of ethics/ conduct. For the five which did not, it is possible that it was an omission, or that the code document does not exist at the organisation. This data $(88.6 \%)$ aligns to that of Pascoe and Welsh (2011) who found that $87 \%$ of Australian companies in the Standard and Poor's list had a publicly transparent WBP that was also linked to their ethical governance framework. Having a code of conduct/ethics and relating that to the organisation's WBP is important because codes of conduct set a standard of behaviour and when violations occur, whistleblowers can report the misconduct, wrongdoing, or unethical behaviour via the WBP. It is important that employees have clarity about the conduct expected of them by their employer, and this clarity is a corporate ethical virtue (Kaptein 2008). Pushing this data towards $100 \%$ compliance will likely require more or better training which emphasises this as best practice.

As mentioned by Pascoe (2010, p. 374), "Setting up an effective whistleblowing program should not be seen as a stand-alone process. Attention should first be given to a company's ethical value system." The current research study indicates that not all Australian companies pay attention to their values. Specifically, a large number $(68.2 \% ; n=30)$ evidenced weak or no alignment of values across their WBP and

\footnotetext{
1 The manuscript for this research study is currently in peer review/under submission (Bramstedt KA. Codes of Conduct and Corporate Values: A Review of Australia's Largest Corporations).
} 
website. Some $(11.4 \% ; n=5)$ have a different/unmatched set of values in their WBP as compared to those listed on their website. Others $(n=12 ; 27.3 \%)$ make no mention of their corporate values in their WBP (either specifically or generically as "values"). Values silence and values miscommunication are problematic as they signal a disconnection that is firstly cognitive and potentially behavioural. WBPs should not be viewed in isolation, rather they are part of a whistleblower management system (WMS) that has a values-based framework. Overtly stating these values and paying attention to ensure they align across all corporate communications is vital so that the corporate voice has congruency (another ethical virtue (Kaptein 2008)) at all levels.

Organisations which use the generic term "values" in their WBP make a weak attempt at linking their corporate values to whistleblowing. As a stand-alone term, "values," is a word that some employees might not understand; however, by including the values by name alongside (e.g., honesty, integrity, safety) they have meaning in the context of expected behaviour as well as wrongdoing.

Placing a hyperlink [in the WBP] to the corporate values positioned elsewhere might satisfy a governance guideline; however, it fails to place the organisation's values in the immediate visual field of the employee. A values hyperlink requires the employee to click it, an extra action they might not do. If they do not click the hyperlink, they will not engage with the ethical value set that is linked to whistleblowing and corporate integrity (and potentially other matters such as customer safety). Also, if the hyperlink dies (i.e., gets corrupted or the document at the end is moved away from the link), then it loses any usefulness and the WBP is entirely devoid of ethical values content.

Some might argue that values statements are merely a public relations tool and have no real value to successful business operations (Collins 2000). Values and other ethical benchmarks (e.g., principles) can set a foundation for ethical behaviour and ethical behaviour has many value-adds for organisations including increasing customer trust and satisfaction (Knauss 2010; Román 2003), reducing the risk of litigation and liability (Kraman and Hamm 1999; Levinson W Trade Practices Commission v CSR Ltd 1991) and reducing employee moral distress (Prottas 2013). With this evidence, it is worthwhile for organisations to optimise their organisational ethics efforts. This includes formulating values statements, aligning the values across corporate policies, and ensuring their visibility to stakeholders. If there is a policy violation, it will be complicated to evaluate behaviour breaches and define meaningful corrective action if corporate values are absent or inconsistent across documents.

\section{Limitations and future studies}

While this research was focused only on large, Australian, for-profit organisations, these research results could be a first step to understanding corporate culture and the values that inform whistleblower policies. Future research could empirically explore the disclosure of corporate values in the not-for-profit sector by exploring their WBPs and code of ethics/conduct cross-referencing as a benchmark for ethical behaviour. In the absence of profit as a goal, one wonders if there is more visibility 
to ethical values in these documents. Future research could also broaden the geographic scope beyond Australia, as well as focus on the reasons why whistleblower policies are sometimes not publicly available (e.g., interviews or surveys with these organisations).

\section{Conclusion}

Expectations of workplace professionalism are influenced by behaviours described in corporate codes of conduct, websites, and other corporate communications. Setting values and ensuring they are operationalised are a foundation of viable corporate governance (MacCormick 2021). Creating a values statement with stakeholder input is only the first step of the process. Values operationalisation is a series of steps which makes the values visible and alive in the organisation, fuelling employee behaviour and corporate outputs (Murphy 1995), potentially building equity of employee citizenship and retention, as well as customer trust.

Whistleblower management systems are inherently value laden, thus it is ethically imperative that their conjoined WBPs visibly voice the values of the organisation, and all associated documents, such as internal behavioural codes and policies align to the values framework. Agreeing with Pascoe and Welsh (2011), whistleblower management systems have legitimacy in the eyes of their stakeholders when organisations are committed to corporate values and their code of ethics.

Supplementary Information The online version contains supplementary material available at https://doi. org/10.1007/s43546-021-00201-2.

Funding Open Access funding enabled and organized by Council of Australian University Librarians (CAUL) and its Member Institutions.

Data availability All data generated or analysed during this study are included in this published article (and its Supplementary Information file).

\section{Declarations}

Ethics approval No research ethics committee review required. Prof Bramstedt is consultant Chief Ethics Officer at Clarity Ethics, a for-profit ethics advisory firm. She also owns a private consultation firm, AskTheEthicist LLC.

Research involved with human or animal participants No human or animal research participants.

Open Access This article is licensed under a Creative Commons Attribution 4.0 International License, which permits use, sharing, adaptation, distribution and reproduction in any medium or format, as long as you give appropriate credit to the original author(s) and the source, provide a link to the Creative Commons licence, and indicate if changes were made. The images or other third party material in this article are included in the article's Creative Commons licence, unless indicated otherwise in a credit line to the material. If material is not included in the article's Creative Commons licence and your intended use is not permitted by statutory regulation or exceeds the permitted use, you will need to obtain permission directly from the copyright holder. To view a copy of this licence, visit http://creativecommons.org/licen ses/by/4.0/. 


\section{References}

ASX. Company Directory (2021) https://www2.asx.com.au/markets/trade-our-cash-market/directory. Accessed 11 March 2021

ASX Corporate Governance Council (2019) Corporate Governance Principles and Recommendations 4th Edition. https://www.asx.com.au/documents/regulation/cgc-principles-and-recommendationsfourth-edn.pdf . Accessed 11 March 2021

Australian Securities \& Investments Commission (2019) Regulatory Guide 270: Whistleblower policies. November 2019. https://download.asic.gov.au/media/5702691/rg270-published-13-november-201920200727.pdf Accessed 11 March 2021.

Collins J (2000) Coye and sons (A): handling a whistleblower. J Legal Stud Educ 18(2):327-336. https:// doi.org/10.1111/j.1744-1722.2000.tb00298.x

Corporations Act 2001 (Cth). https://www.legislation.gov.au//Details/C2019C00216

Dixon O (2016) Honesty without fear? Whistleblower anti-retaliation protections in corporate codes of conduct. Melb Univ Law Rev 40(1):168-206

Forbes (2021) GLOBAL 2000: world's largest public companies. https://www.forbes.com/global2000/\# 18bf0cbe335d. Accessed 11 March 2021

Kaptein M (2008) Developing and testing a measure for the ethical culture of organizations: the corporate ethical virtues model. J Organ Behav 29(7):923-947. https://doi.org/10.1002/job.520

Knauss D (2010) The role of business ethics in relationships with customers, Forbes 19 Jan 2010. https:// www.forbes.com/2010/01/19/knauss-clorox-ethics-leadership-citizenship-ethics.html?sh=58aa1 eda7279

Kraman S, Hamm G (1999) Risk management: Extreme honesty may be the best policy. Ann Intern Med 131(12):963-967. https://doi.org/10.7326/0003-4819-131-12-199912210-00010

Levinson W Trade Practices Commission v CSR Ltd (1990) FCA 762; [1990] FCA 521; (1991) 13 ATPR 41-076 (20 December 1990)

MacCormick J (2021) Cultural awareness. Co Director 37:24-25

Murphy PE (1995) Corporate ethics statements: current status and future prospects. J Bus Ethics 14(9):727-740. https://www.jstor.org/stable/25072692

Pascoe J (2010) Corporate sector whistleblowing in Australia-some empirical evidence. Keep Good Co $62: 374$

Pascoe J, Welsh M (2011) Whistleblowing, ethics and corporate culture: theory and practice in Australia. Common Law World Rev 40(2):144-173. https://doi.org/10.1350/clwr.2011.40.2.0213

Prottas DJ (2013) Relationships among employee perception of their manager's behavioral integrity, moral distress, and employee attitudes and well-being. J Bus Ethics 113(1):51-60. https://doi.org/ $10.1007 / \mathrm{s} 10551-012-1280-\mathrm{z}$

Román S (2003) The impact of ethical sales behaviour on customer satisfaction, trust and loyalty to the company: an empirical study in the financial services industry. J Market Mgmt 19(9-10):915-939. https://doi.org/10.1080/0267257X.2003.9728245 